\title{
Recent Development on Social Media Usage for the Evaluation of Library Users' Satisfaction
}

\author{
Siti Rinawaty Awang Ali \\ Faculty of Information Management, \\ Universiti Teknologi MARA (UiTM), \\ UiTM Selangor, Malaysia \\ Wan Nor Haliza Wan Mokhtar \\ Faculty of Information Management, \\ Universiti Teknologi MARA (UiTM), \\ UiTM Selangor, Malaysia \\ Tengku Adil Tengku Izhar \\ Faculty of Information Management, \\ Universiti Teknologi MARA (UiTM), \\ UiTM Selangor, Malaysia
}

Received: April 17, 2021 Accepted: June 1, 2021 Published: July 2, 2021

doi:10.5296/ijssr.v9i2.18826 URL: https://doi.org/10.5296/ijssr.v9i2.18826

\begin{abstract}
In this digital era of technology, social media has become part of our lives. Human beings communicate with each other using technology, as well as through social media these days. Social media has become a common medium for people to interact and communicate with each other via the internet application. At the same time, Social media is one of the communication tools and also promotional tools for public libraries nowadays. The purpose of this study is to investigate and examine the users' satisfaction towards library social media usage. In order to achieve this purpose, this paper aims to evaluate current development in social media usage in the library section as an effort to evaluate the users' satisfaction.
\end{abstract}

Keywords: library, literature review, social media, users' satisfaction 


\section{Introduction}

Social media can be referred to as user-generated content which this characteristic can be found in social media platforms like Facebook, Twitter, YouTube, Instagram, etc. Social media offers a variety of features that facilitate socialization, which allows users to share public musings and express their emotions through photos, music, videos, and private messages. Researchers stated that these are the most visited site on the internet and have grown rapidly in the past few years (Alexa, 2008). Statista Research Department (statista.com) reported that in the year 2020, eighty-one percent (81\%) of the Malaysian population are active social media users and Facebook is the leading social media platform that is popular among Malaysians.

Based on the Cambridge Dictionary (2020), social media is defined as "websites and computer programs that allow people to communicate and share information on the internet using a computer or mobile phone". In the early age of the internet, the World Wide Web was one-sided with most websites providing only static information (Goh et al., 2013). However, in the early 2000 people tended to communicate on the internet not only by listening and reading the information. They want to give comments, ask questions and write something on the web and this is when the internet was called Social Web or Web 2.0 (Kaplan \& Haenlein, 2010).

The library is a non-profit organization also taking this opportunity to adopt social media as one of a medium to disseminate information and integrate social networking and promote services to their users. However, can these platforms cater to the users' satisfaction? How about the dissemination of information over the internet, can it reach the users? There are many issues related to social media nowadays, so with this in mind, the researcher intends to investigate and examine the users' satisfaction towards library social media platforms. At the end of the study, a framework for the public library related to users' satisfaction towards social media applications will be produced.

\section{Literature Review}

There are few passed research conducted by many researchers previously. For example, Fasola (2015) highlights social media perception and acceptance. However, it was a librarian-focused study and they conducted the study generally for all types of libraries in Nigeria. Besides that, Joo et al. (2018) have conducted a study related to the public library usage of social media focusing on Facebook only and investigated the content of Facebook posts and the relationship with library users. Yet, the research was conducted by investigating the social media itself and not a user-centered type of research. There is another research conducted to explore social media usage in academic libraries in South Africa, but again the study is focusing on academic libraries only. The study was conducted by Williams et al. (2019) and it was focusing on the rural area. On the other hand, Xie and Stevenson (2014) say that general research was completed for digital libraries in North America and Europe to investigate the applications of social media in digital libraries to identify related problems. Nonetheless, the issues highlighted in this research have critically analyzed the institution or the digital libraries that adopt social media only and not to the users' perception. 


\subsection{Privacy Issues in Social Media}

Discussing privacy issues is always related to the public trust issue. Gomez and Gould (2010) categorized trust into four categories which are safety, relevance, reputation, and "cool". According to these researchers, libraries tend to be the most reputable public access to information communication and technology (ICT). However, safety in the libraries tends to be the lowest although in social safety the library is always perceived as an acceptable place for women and children. To relate this with social media, Ur and Wang (2013) stated in their research that privacy behaviors and attitudes can be influenced by the users' trust in data-protection practices by the government and social media providers.

\subsection{Digital Literacy}

Additionally, Khan (2020) highlighted in his research that training programs for computer literacy must be held to encourage users to use social media platforms in the library. This is because his research findings indicate that the correspondents have a low level of current digital information literacy. Meanwhile, there is research on public libraries and the social web which reveals that there are six major recurring themes in the research analysis including implications for information and digital literacy (Carlsson, 2015). Although the percentage is low compared to other major themes, it is still a gap for libraries to take into consideration to use social media as a new facet of public librarianship.

\subsection{Digital Divide}

Nyahodza and Higgs (2017) indicate that there are two levels of digital divide consist of the global and local digital divide, and with this theory, Williams et. al (2019) conclude that these digital inequalities are caused by financial restraints. They also said that this restraint has impacted the adoption of social media in libraries. Meanwhile, Audunson et al. (2019) point out in their research that it is the role of libraries to secure the internet and evening out the digital divide. But how can these be achievable in a third-world country? Islam and Tsuji (2011) discover that it is when there is a say that countries that suffer the most with financial hardship are considered third-world countries.

\subsection{Inactive Library’s Social Media Sites}

The research revealed that many libraries' social media profiles are inactive, and they found out that some of the profiles have not been updated since it was created (Fasola, 2015). These will impact the users' satisfaction and cause them to unfollow the library's social media site. This issue was also raised by Xie and Stevenson (2014) in their study. They also stated that a lack of standard in sense of identity can make confusions among users when there are social media posts with cross-linked institutions.

\section{Methodology}

The target population in the study comprised of the professional librarians and the social media users of public libraries. Data collection methods based on questionnaires, interviews and observations. Using SPSS as the analysis tools and Roasoft Calculator to identify the sample size. 


\section{Discussion and Contribution}

This contribution is based on theory development and advancement of existing theory with some logic and facts. A theoretical framework is developed to support the theory and to explain why the research problem exists. Expectations of the users are important to help the library to improve their services and to fulfill their users' satisfaction. Since this research is a user-centered type, it will analyze the expectation and perception from the users' perspective. Hence, the result of this research will help the library to draw a guideline for the library references in using social media platforms as their information dissemination tool.

The users' needs can be determined when this research is conducted, and this will help the library to better understand their users and make use of their needs in developing a service. The library can develop a service based on the research output to fulfill their users' needs. This research will identify the digital divide existence in every branch of Sabah State Library which will be a guide for the library to ensure that their Information and Communication Technology (ICT) facilities are available. The library also can develop a service to reduce digital inequality and digital literacy among the users in the area.

Helping public libraries in determining suitable mediums or platforms to interact with their users. The output of this research will determine what kind of posting on social media attract the users more. There are many types and formats of posting on social media such as text, images, videos to disseminate information. So, the library can do their posting based on their users' preferences.

Increasing users' satisfaction through social media sites is one of the major contributions in this research. This research output will determine what are factors contribute to the failure of communication through social media platforms which will lead to dissatisfaction among users. The feedback from the users can be analyzed and the output can be used by the library to do what needs to be done for their improvement.

Improving service quality to the users from time to time is as crucial as increasing their users' satisfaction. Hence, this research output will help the library to examine the service provided and make improvements in their service quality. Services also need to be updated from time to time according to the users' needs. If this is done by the library, the users' satisfaction can be increased with no doubt.

\section{Conclusion}

In a summary, social media is one of the communication tools and also promotional tools for public libraries nowadays and this chapter discussed the issues related to social media which are including privacy issues in social media, digital literacy, digital divide, and inactive library social media sites. The researcher intends to investigate and determine the users' satisfaction with the public library's social media. Towards the end of this research, the researcher explained how can this research benefited the public libraries as a whole and specifically Sabah State Library because the scope for this research is the public libraries in Sabah, Malaysia. The research objectives and research questions will be a user-centric type of research that will focus on the users for the library's references. 


\section{References}

At, L., Repositoriesmalaysian, I., Universities, P., Library, N. N. E., Malaya, U., \& Lumpur, K. (2009). Journal PPM, 3(2002).

Audunson, R., Aabø, S., Blomgren, R., Evjen, S., Jochumsen, H., Larsen, H., ... Koizumi, M. (2019). Public libraries as an infrastructure for a sustainable public sphere: A comprehensive review of research. Journal of Documentation, 75(4), 773-790. https://doi.org/10.1108/JD-10-2018-0157

Carlsson, H. (2015). Researching public libraries and the social web, 2006-2012. Journal of Documentation, 71(4), 632-649. https://doi.org/10.1108/JD-03-2014-0046

Fasola, O. S. (2015). Perceptions and acceptance of librarians towards using Facebook and Twitter to promote library services in Oyo State. Electronic Library, 33(5), 870-882. https://doi.org/10.1108/EL-04-2014-0066

Goh, W. W., Hong, J. L., \& Goh, K. S. (2013). Students' behavior and perception of using Facebook as a learning tool (pp. 731-736). Proceedings of the 8th International Conference on Computer Science and Education, ICCSE 2013, Iccse. https://doi.org/10.1109/ICCSE.2013.6554004

Gomez, R., \& Gould, E. (2010). The “cool factor" of public access to ICT: Users' perceptions of trust in libraries, telecentres and cybercafés in developing countries. Information Technology and People, 23(3), 247-264. https://doi.org/10.1108/09593841011069158

Islam, M. A., \& Tsuji, K. (2011). Bridging digital divide in Bangladesh: Study on Community Information Centers. Electronic Library, 29(4), 506-522. https://doi.org/10.1108/02640471111156768

Joo, S., Choi, N., \& Baek, T. H. (2018). Library marketing via social media: The relationships between Facebook content and user engagement in public libraries. Online Information Review, 42(6), 940-955. https://doi.org/10.1108/OIR-10-2017-0288

Kaplan, A. M., \& Haenlein, M. (2010). Users of the world, unite! The challenges and opportunities of Social Media. Business Horizons, 53(1), 59-68. https://doi.org/10.1016/j.bushor.2009.09.003

Khan, A. (2020). Digital information literacy skills of Pakistani librarians: Exploring supply-demand mismatches, adoption strategies and acquisition barriers. Digital Library Perspectives, 36(2), 167-189. https://doi.org/10.1108/DLP-01-2020-0003

MCMC. (2018). Internet users survey 2018: Statistical brief number twenty-three. Internet Users Survey, 1-39. Retrieved from https://www.mcmc.gov.my/skmmgovmy/media/General/pdf/Internet-Users-Survey-2018.pdf Nyahodza, L., \& Higgs, R. (2017). Towards bridging the digital divide in post-apartheid South Africa: a case of a historically disadvantaged university in Cape Town. South African Journal of Libraries and Information Science, 83(1), 39-48. 


\section{Macrothink

https://doi.org/10.7553/83-1-1645

Ur, B., \& Wang, Y. (2013). A cross-cultural framework for protecting user privacy in online social media (pp. 755-762). WWW 2013 Companion - Proceedings of the 22nd International Conference on World Wide Web. https://doi.org/10.1145/2487788.2488037

Williams, M. L., Dhoest, A., \& Saunderson, I. (2019). Social media, diffusion of innovations, morale and digital inequality: A case study at the University of Limpopo Libraries, South Africa. Library Hi Tech, 37(3). https://doi.org/10.1108/LHT-12-2018-0192

Xie, I., \& Stevenson, J. (2014). Social media application in digital libraries. Online Information Review, 38(4), 502-523. https://doi.org/10.1108/OIR-11-2013-0261

\section{Copyrights}

Copyright for this article is retained by the author(s), with first publication rights granted to the journal.

This is an open-access article distributed under the terms and conditions of the Creative Commons Attribution license (http://creativecommons.org/licenses/by/4.0/). 